\title{
PENGARUH REPETITIVE TRANSCRANIAL MAGNETIC STIMULATION (RTMS) TERHADAP GANGGUAN FUNGSI KOGNITIF PASCASTROKE ISKEMIK
}

\author{
THE INFLUENCE OF REPETITIVE TRANSCRANIAL MAGNETIC \\ STIMULATION (RTMS) TOWARDS IMPAIRED COGNITIVE FUNCTION \\ AFTER ISCHEMIC STROKE
}

Novika Azirah Azis, * Jumraini Tammasse, * Abdul Muis*

\section{ABSTRACT}

Introduction: The increasing number of ischemic stroke patients who experience memory disturbances and a long rehabilitation process requires an innovation that can strengthen both existing therapies (medical therapy) and noninvasive stimulation of cognitive rehabilitation in the form of repetitive transcranial magnetic stimulation (rTMS).

Aim: To determine effectiveness of $r$ TMS towards impaired cognitive function in ischemic stroke.

Methods: This research was conducted using experimental with open clinical trial test method on ischemic stroke patients suffering from cognitive impairment at Wahidin Sudirohusodo Hospital and Inggit Clinic, Makassar, from November 2018 until January 2019. Samples were divided into control who was given only medical therapy and treatment group who was given medical therapy and rTMS. Stimulation is given in the form of a high frequency of $10 \mathrm{~Hz}$ in 2 cycles for 5 consecutive days with a gap of 2 days. MoCA-Ina was used to assess cognitive impairment. The assessment were made on day-1 before therapy and day-15 after therapy. The statistical analysis of correlation among variables was conducted by using Chi-square test with value of $p<0.05$ which was considered significant.

Results: There were 22 samples, 11 in each group. The difference of MoCA-Ina scores in both groups with the final average after 15 days of treatment was 5.27 in the treatment group and 1.45 in control group. This difference is considered significant with the $p$ value of 0.003 .

Discussion: There was an effect of rTMS therapy on cognitive function disorders after ischemic stroke, in which the change was greater in the treatment group than in the control group.

Keywords: Cognitive impairment, ischemic stroke, Montreal Cognitive Assesment Indonesian Version (MoCA-Ina), repetitive transcranial magnetic stimulation (rTMS)

\section{ABSTRAK}

Pendahuluan: Peningkatan jumlah pasien stroke iskemik yang mengalami gangguan memori serta proses rehabilitasi yang lama membutuhkan suatu inovasi yang dapat saling menguatkan antara terapi yang sudah ada (terapi medik) dan stimulasi non-invasif rehabilitasi kognitif berupa repetitive transcranial magnetic stimulation (rTMS).

Tujuan: Mengetahui pengaruh intervensi rTMS terhadap fungsi kognitif pascastroke iskemik.

Metode: Penelitian eksperimental dengan uji klinis terbuka terhadap pasien stroke iskemik yang menderita gangguan fungsi kognitif di RSUP Dr. Wahidin Sudirohusodo dan Klinik Inggit Medika, Makassar, pada bulan November 2018 hingga Januari 2019. Subjek dibagi ke dalam kelompok kontrol yang diberikan terapi medikamentosa saja serta kelompok perlakuan yang diberikan terapi medikamentosa dan intervensi rTMS. Stimulasi diberikan berupa frekuensi tinggi $10 \mathrm{~Hz}$ dalam 2 siklus selama 5 hari berturut-turut dengan jeda waktu 2 hari. Penilaian gangguan kognitif menggunakan Montreal Cognitive Assesment versi Indonesia (MoCA-Ina). Pengukuran dilakukan pada hari-1 pre-terapi dan hari ke-15 pascaterapi. Data dianalisis secara statistik menggunakan uji Chi-square dengan nilai $\mathrm{p}<0,05$ dianggap bermakna.

Hasil: Terdapat 22 subjek yang masing-masing terdiri dari 11 subjek pada kelompok kontrol dan perlakuan. Selisih skor MoCA-Ina pada kedua kelompok dengan rerata akhir setelah lima belas hari perlakuan sebesar 5,27 pada kelompok perlakuan dan 1,45 pada kelompok kontrol yang bermakna $(\mathrm{p}=0,003)$.

Diskusi: Terdapat pengaruh terapi rTMS terhadap gangguan fungsi kognitif pascastroke yang lebih besar pada kelompok perlakuan dibanding kelompok kontrol.

Kata kunci: Gangguan kognitif, Montreal Cognitive Assesment versi Indonesia (MoCA-Ina), repetitive transcranial magnetic stimulation (rTMS), stroke iskemik

*Bagian Neurologi FK Universitas Hasanuddin, Makassar. Korespondensi: oshinfamous@gmail.com. 


\section{PENDAHULUAN}

Stroke menyebabkan disfungsi neuromuskular yang mengakibatkan disabilitas, seperti apraksia, spastisitas tungkai, dan inkontinensia urin. Sebagai tambahan, pasien stroke menderita gangguan fungsi kognitif, termasuk penurunan memori, penurunan fungsi bahasa, ketidakmampuan menyelesaikan masalah, dan pemikiran yang tidak terorganisir. Berbagai macam intervensi dilakukan untuk meminimalkan komplikasi neurologis akibat stroke. Pada proses akhir rehabilitasi, terapi restorasi seperti terapi berbasis sel, stimulasi elektromagnetik, dan pendekatan berorientasi tugas terbukti bermanfaat bagi pasien stroke. ${ }^{1}$

Gangguan kognitif sangat memengaruhi kehandalan manusia dalam mengerjakan suatu pekerjaan yang dapat berlanjut menjadi demensia, delirium, dan amnesia sebagai bentuk klinis paling berat yang mengganggu aktivitas, pekerjaan, dan fungsi sosial seseorang. ${ }^{2}$

Rehabilitasi penurunan memori terdiri dari pelatihan ulang memori, alat bantu memori eksternal, dan strategi pembelajaran khusus. Namun, rehabilitasi ini membutuhkan waktu yang cukup lama dan hasil akhir yang tidak optimal jika kepatuhan pasien buruk. Teknologi stimulasi otak non-invasif terkini, repetitive transcranial magnetic stimulation (rTMS), menawarkan rehabilitasi kognitif dan memori melalui pemberian stimulasi berulang di area otak yang spesifik, hingga mengaktifkan neuron-neuron aksis horizontal. ${ }^{1}$

Penggunaan rTMS dapat meningkatkan memori melalui brain nucleotide neurotrophic factor (BDNF) dengan mememodulasi plastisitas sinapssinaps neural. BDNF terlibat dalam pengontrolan koneksi neuron, pengembangan regulasi sinaps, dan memperkuat plastisitas sinaps. Bahkan, polimorfisme nukleotid Val66Met pada gen BDNF dipercaya berkorelasi dengan korteks prefrontal, volume hipokampus, dan fungsi memori. ${ }^{1}$

Dihipotesiskan penggunaan rTMS pascastroke dapat meningkatkan induksi plastisitas di dalam otak dan bila dikombinasikan dengan terapi manual, dapat memfasilitasi neuron yang bertahan dari fungsinya yang hilang akibat stroke. ${ }^{3}$ Claflin dkk menemukan bahwa rTMS frekuensi rendah akan mengurangi aktivitas neuron kortikal dan rTMS frekuensi tinggi akan meningkatkan eksitabilitas neuron. ${ }^{4-5}$

Meningkatnya jumlah pasien stroke iskemik yang mengalami gangguan memori serta proses rehabilitasi yang lama menyebabkan dibutuhkannya suatu inovasi yang saling menguatkan antara terapi yang sudah ada (terapi medik) dan stimulasi noninvasif rehabilitasi kognitif berupa rTMS. ${ }^{5}$ Pedoman penggunaan terapi rTMS pada stroke menyebutkan bahwa intensitas stimulasi sub-motor threshold sudah cukup untuk memicu eksitabilitas korteks. ${ }^{6}$

Pengaruh pemberian frekuensi rendah atau tinggi pada gangguan fungsi kognitif belum terlalu jelas, sehingga membutuhkan penelitian lebih lanjut. Studi Atteya dkk mengenai pengaruh rTMS frekuensi yang berbeda pada fungsi kognitif pasien stroke menyatakan bahwa pemberian intervensi rTMS pada $10 \mathrm{~Hz}$ dan $5 \mathrm{~Hz}$ memberikan peningkatan kecepatan aliran darah (blood flow velocity) sebesar 19,68\% dan 10,98\% dibandingkan tanpa intervensi rTMS (aerobik+fisioterapi) sebesar 7,35\%. ${ }^{7}$

Pada pengukuran korelasi koefisien antara addenbrookes cognitive examination dan aliran darah didapatkan perbedaan yang bermakna pada grup intervensi rTMS $10 \mathrm{~Hz}(\mathrm{p}=0,006)$ dan $5 \mathrm{~Hz}$ $(\mathrm{p}=0,027)$, tanpa perbedaan bermakna pada grup tanpa intervensi rTMS $(\mathrm{p}=0,534){ }^{7}$ Oleh karena itu, dilakukan penelitian pengaruh pemberian intervensi rTMS frekuensi rendah maupun frekuensi tinggi pada gangguan kognitif, khususnya pada penderita iskemik stroke.

\section{TUJUAN}

Mengetahui pengaruh rTMS terhadap fungsi kognitif pascastroke iskemik berdasarkan Montreal Cognitive Assesment versi Indonesia (MoCA-Ina).

\section{METODE}

Penelitian desain eksperimental berupa uji klinis terbuka (open trial) terhadap pasien stroke iskemik di Unit rawat inap/jalan RSUP Dr. Wahidin Sudirohusodo dan Klinik Inggit Medika, Makassar. Sampel diperoleh secara konsekutif pada bulan November 2018 hingga Januari 2019. 
Kriteria inklusi meliputi penderita stroke iskemik awitan 2 minggu sampai 1 tahun yang didukung dengan hasil CT scan kepala, mengalami gangguan kognitif berdasarkan skor MoCA-Ina $<26$; berusia 35-70 tahun; fungsi memori normal sebelum terjadinya stroke iskemik; serta tidak ada gangguan kesadaran, kelainan fungsi hati, paru, jantung, atau ginjal yang berat. Adapun kriteria eksklusi meliputi pasien dengan Alzheimer-ringan, demensia, atau sedang mengonsumsi donepezil (penghambat asetilkolinesterase).

Subjek dibagi ke dalam kelompok kontrol yang diberikan terapi medikamentosa saja serta kelompok perlakuan yang diberikan terapi medikamentosa dan rTMS. Subjek pada kelompok perlakuan mendapat intervensi rTMS dalam 2 siklus. Setiap siklus dilakukan selama 5 hari berturut-turut dengan jeda waktu 2 hari kemudian dilanjutkan siklus kedua selama 5 hari berturut-turut.

Metode rTMS ini berdasarkan pada pembuatan variabel medan magnet ke seluruh permukaan kulit kepala subjek penelitian, yang menyebabkan arus listrik sementara pada permukaan kortikal dan memodulasi fungsi neuron yang berada tepat di bawah coil, dan menghubungkan regio-regio otak lainnya. Stimulasi rTMS pada frekuensi rendah mengurangi eksitabilitas kortikal, sedangkan pada frekuensi tinggi memfasilitasi eksitabilitas neuronal. ${ }^{8}$ Frekuensi rendah diberikan pada ipsi lesi, sedangkan frekuensi tinggi diberi pada kontra lesi.
Subjek perlakuan menerima stimulasi rTMS frekuensi tinggi $10 \mathrm{~Hz}$ dengan intensitas $80-100 \%$ ambang rangsang motorik (motor threshold/MT) pada area dorso lateral prefrontal korteks kiri, dan frekuensi rendah $1 \mathrm{~Hz}$ dengan intensitas $80-100 \%$ MT pada area dorsolateral prefrontal korteks kanan. Ambang rangsang motorik didefinisikan sebagai intensitas minimum yang masih dapat memberikan motor-evoked potential pada area target. ${ }^{6,9}$

Adapun subjek pada kelompok kontrol hanya mendapat terapi standar stroke iskemik, yaitu medikamentosa dan terapi rTMS. Subjek kontrol menerima stimulasi rTMS dengan letak lempeng coil tegak lurus kulit kepala untuk meniru prosedur terapi, namun tidak menginduksi kumparan magnet ke dalam otak. Terapi diberikan oleh orang yang sama, medikamentosa yang diberikan juga sama antar kelompok. Analisis data dilakukan dengan program SPSS versi 17 yang disajikan dalam bentuk tabel dan grafik.

\section{HASIL}

Didapatkan 22 subjek yang terdiri dari masing-masing 11 subjek pada kelompok kontrol dan perlakuan. Kedua kelompok subjek memiliki rerata usia yang sama, 57 tahun, mayoritas lakilaki, berpendidikan $>9$ tahun, lokasi lesi terutama di hemisfer dekstra, serta nilai rerata MoCA-Ina yang tidak berbeda bermakna (Tabel 1).

Sebelum terapi medikamentosa pada hari-1 pengukuran menunjukkan rerata skor MoCA-Ina

Tabel 1. Karakteristik Demografi Subjek Penelitian $(n=22)$

\begin{tabular}{|c|c|c|c|c|}
\hline \multirow{2}{*}{ Karakteristik } & \multicolumn{2}{|c|}{ Perlakuan $(n=11)$} & \multirow[b]{2}{*}{ Rerata \pm SD } & \multirow{2}{*}{$\mathbf{p}^{*}$} \\
\hline & n (\%) & Rerata \pm SD & & \\
\hline Usia (thn) & & $57,18 \pm 7,414$ & $57,73 \pm 8,23$ & 0,453 \\
\hline Awitan (bln) & & $6,27 \pm 2,195$ & $5,18 \pm 2,96$ & 0,577 \\
\hline $\begin{array}{l}\text { Jenis Kelamin } \\
\text { - Laki-laki } \\
\text { - Perempuan }\end{array}$ & $\begin{array}{l}8(72,7 \%) \\
3(27,3 \%)\end{array}$ & $\begin{array}{l}- \\
-\end{array}$ & $\begin{array}{l}- \\
-\end{array}$ & 0,647 \\
\hline $\begin{array}{l}\text { Pendidikan } \\
\bullet \leq 9 \text { tahun } \\
\bullet>9 \text { tahun }\end{array}$ & $\begin{array}{l}4(36,36 \%) \\
7(63,63 \%)\end{array}$ & - & $\begin{array}{l}- \\
-\end{array}$ & 0,416 \\
\hline $\begin{array}{l}\text { Hemisfer } \\
\text { - Dekstra } \\
\text { - Sinistra }\end{array}$ & $\begin{array}{l}7(63,63 \%) \\
4(36,36 \%)\end{array}$ & $\begin{array}{l}6(54,54 \%) \\
5(45,45 \%)\end{array}$ & $\begin{array}{l}- \\
-\end{array}$ & 0,665 \\
\hline Skor MoCA-Ina Awal & & $15,18 \pm 5,689$ & $14,27 \pm 3,58$ & 0,416 \\
\hline
\end{tabular}

*Uji Chi-square; n: jumlah sampel; SD: standar deviasi; MoCA-Ina: Montreal Cognitive Assesment versi Indonesia. 
$14,27 \pm 3,580$ (Tabel 2) yang meningkat menjadi $15,73 \pm 3,133$ di hari ke-15 pada kelompok kontrol, sehingga didapatkan selisih skor $1,45 \pm 1,036$. Nilai rerata skor MoCA-Ina pada hari ke-15 lebih besar dibandingkan dengan rerata pada hari ke-1 kelompok kontrol yang bermakna $(\mathrm{p}=0,001)$. peningkatan fungsi memori kerja dan fungsi evokasi subjek. Dari tes MoCA-Ina didapatkan peningkatan skor MoCA-Ina pascaintervensi TMS dari 18,7 $\pm 3,4$ sebelum terapi yang meningkat menjadi $21,1 \pm 4,03$. Hal ini sejalan dengan Lu dkk, bahwa stimulasi rTMS pada regio lobus prefrontal dapat mengaktivasi daerah

Tabel 2. Skor MoCA-Ina Hari Ke-1 dan Ke-15 pada Kedua Kelompok (n=22)

\begin{tabular}{lcccc}
\hline \multirow{2}{*}{ Hari Pengukuran } & \multicolumn{2}{c}{ Kelompok Kontrol $(\mathbf{n}=11)$} & \multicolumn{2}{c}{ Kelompok Perlakuan $(\mathbf{n}=11)$} \\
\cline { 2 - 5 } & \multicolumn{2}{c}{ Rerata \pm SD } & $\mathbf{p}^{*}$ & \multicolumn{2}{c}{ Rerata \pm SD } & $\mathbf{p}^{*}$ \\
\hline - Hari ke-1 & $14,27 \pm 3,580$ & 0,001 & $15,18 \pm 5,689$ & 0,0001 \\
- Hari ke-15 & $15,73 \pm 3,133$ & & $20,45 \pm 5,298$ & \\
$\Delta$ Skor & $1,45 \pm 1,036$ & & $5,27 \pm 0,905$ & \\
\hline *Ujit & &
\end{tabular}

*Uji t tidak berpasangan; SD: standar deviasi; MoCA-Ina: Montreal Cognitive Assesment versi Indonesia.

Sebelum terapi medikamentosa dan rTMS pada hari-1 kelompok perlakuan didapatkan rerata skor MoCA-Ina 15,18 $\pm 5,689$ yang meningkat menjadi 20,45 $\pm 5,298$; sehingga didapatkan selisih

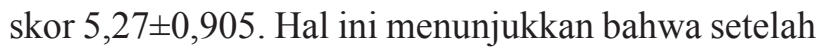
pemberian terapi, rerata skor MoCA-Ina pada hari ke-15 lebih besar dibandingkan dengan hari ke-1 kelompok perlakuan yang bermakna $(\mathrm{p}=0,0001)$.

Perbandingan selisih skor MoCA-Ina pada kelompok perlakuan lebih besar dibandingkan dengan

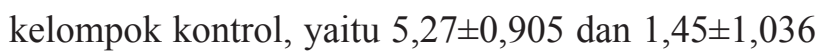
poin, yang berbeda bermakna $(\mathrm{p}=0,003)$ berdasarkan uji Pearson Chi-square. Hal ini berarti perubahan peningkatan fungsi kognitif pascastroke iskemik lebih besar pada kelompok dengan perlakuan rTMS dibandingkan dengan kelompok kontrol yang hanya mendapatkan terapi standar stroke iskemik.

\section{PEMBAHASAN}

Usia dan jenis kelamin sering dikaitkan dengan prevalensi stroke iskemik. Pada penelitian ini dilakukan pengendalian variabel pada kelompok usia, faktor risiko, dan terapi lainnya dengan $p>0,05$ yang berarti variabel demografi tidak berbeda bermakna pada kedua kelompok. Mayoritas subjek penelitian ini adalah laki-laki (68,18\%), sejalan dengan penelitian Lu dkk tentang gangguan kognitif pascastroke dan rTMS, bahwa laki-laki lebih banyak dibandingkan perempuan, yaitu $62,5 \%{ }^{1}$

Pada penelitian ini dilakukan stimulasi rTMS di daerah korteks prefrontal untuk memberikan hipokampus melalui struktur subkortikal dan korteks posterior, hingga meningkatkan fungsi kognitif dan meregulasi proses ekstraksi memori. Pada 40 sampel, setelah 4 minggu terapi rTMS dan pengobatan stroke iskemik berdasarkan rekomendasi AHA/ASA 2008, tingkat respons dan pemulihan fungsi kognitif lebih baik dibandingkan dengan plasebo $(\mathrm{p}<0,001)$, bahkan setelah 2 bulan pascaterapi berdasarkan skor MoCA dan skor Loewenstein Occupational Therapy Cognitive Assessment (LOTCA). ${ }^{1}$

Penurunan fungsi kognitif, mulai dari penurunan rekognisi tingkat sedang hingga demensia, bisa disebabkan oleh penyakit serebrovaskuler seperti infark serebri, leukoaraiosis, dan iskemia serebri yang kronik. Kebanyakan pasien dengan penyakit serebrovaskuler memiliki demensia, sehingga menurunkan fungsi memori dengan cepat. Penelitian dengan pemantauan selama 5 tahun mengungkapkan bahwa penurunan memori selama intervensi merupakan indikator penting non-demensia yang berkembang menjadi demensia. ${ }^{1}$

Miniussi dkk menyatakan bahwa TMS memengaruhi langsung korteks motorik primer dan menginduksi aktivasi traktus kortikospinal, yaitu traktus yang memproduksi motor evoked potential (MEP). ${ }^{9}$ Secara umum, terdapat dua keuntungan dari TMS adalah 1) dapat diberikan pada subjek dengan skala besar, pada frekuensi tinggi secara terus menerus dengan efek samping minimal; serta 2) lokasi coil dapat dikontrol dengan pendekatan neuronavigasi untuk mengetahui letak lesi agar stimulasi 
diutamakan pada region terpilih. Penting untuk menentukan keadaan fungsional anatomi pada tiap subjek dan menentukan area yang rusak, keadaan neurofisiologis, dan korteks perilesional. Mekanisme perbaikan dari stroke berkaitan dengan tipe dari kerusakannya, menggunakan strategi kognitif yang potensial serta kombinasi dari stimulasi otak di regio terpilih merupakan pilihan paling utama. ${ }^{10}$

Studi Luber dkk mendapatkan 61 contoh peningkatan kinerja yang berhubungan dengan TMS, antara lain peningkatan diskriminasi perseptual dan motor-learning, pergerakan bola mata dan identifikasi objek, serta kinerja pada bagian utama yang terlibat dalam atensi, memori, dan bahasa. Peningkatan kinerja menggunakan TMS dalam berbagai paradigma, termasuk pemakaian TMS single pulse, theta-burst, trains-rTMS frekuensi tinggi maupun rendah, baik $10 \mathrm{~Hz}$ atau $5 \mathrm{~Hz} \cdot{ }^{11-12}$

Ritme theta rTMS didapatkan mampu memengaruhi sebagian besar regio otak yang berperan terhadap kinerja memori dan atensi, sehingga terjadi peningkatan fungsi kognitif, khususnya fungsi eksekutif dengan menggunakan stimulasi 5Hz. Keuntungan pemberian TMS yang lain juga didapatkan pada studi terhadap orang muda sehat. Lie dkk mendapatkan pemberian stimulasi $10 \mathrm{~Hz}$ di daerah spesifik (korteks dorsolateral prefrontal) secara berkala pada orang muda sehat, tidak hanya memulihkan neural di daerah prefrontal korteks, namun juga meningkatkan efisiensi pemecahan masalah yang lebih kompleks dan bertahap pada proses pengontrolan kognitif. ${ }^{11-12}$

Penelitian ini telah berusaha mengurangi bias dengan melakukan "matching" variabel demografi umur, jenis kelamin, awitan, dan terapi standar termasuk penggunaan obat-obatan, namun tetap memiliki keterbatasan, antara lain kesulitan yang ditemui untuk mengumpulkan subjek penelitian sesuai kriteria inklusi dalam waktu yang relatif singkat, sehingga tidak dilakukan "blind" terhadap pasien dan teknisi rTMS.

\section{KESIMPULAN}

Terapi rTMS dapat memberikan perbaikan gangguan fungsi kognitif pascastroke iskemik.

\section{DAFTAR PUSTAKA}

1. Lu H, Zhang T, Wen M, Sun L. Impact of repetitive transcranial magnetic stimulation on post-stroke dysmnesia and role of BDNF Val66Met SNP. Med Sci Monit. 2015;21:761-8.

2. Wreksoatmodjo BR. Aktivitas kognitif mempengaruhi fungsi kognitif lanjut usia di Jakarta. CDK. 2014;41(3).

3. Matheson NA, Jon BH, Shemmell, Dirk DR, John NJR. Understanding the effects of repetitive transcranial magnetic stimulation on neuronal circuits. Front Neural Circuits. 2016;10:67.

4. Jiang L, Xiang-Min M, Ru-Yi L, Ru Z, Zheng Z, YiFeng D. Effect of different frequencies of repetitive transcranial magnetic stimulation on the recovery of upper limb motor dysfunction in patients with subacute cerebral infarction. Neural Regen Res. 2016;11(10):1584-90.

5. Claflin ES, Krishnan C, Khot SP. Emerging treatment for motor rehabilitation after stroke. Neurohospitalist. 2015;5(2):77-88.

6. Lefaucheur JP, Andre ON, Antal A, Ayache SS, Baeken C, Benninger DH, dkk. Evidence-based guideline on the therapeutic use of repetitive transcranial magnetic stimulation (rTMS). Clin Neurophysiol. 2014;125(11):2150-206.

7. Atteya A, Ebtisam MF, Hebatallah RMR, Tahani FM, Sandra MA, dkk. The effect of different frequencies of transcranial magnetic stimulation combined with aerobic exercise on cognitive function in stroke patients. Int J Chemtech Res. 2017;10(5):418-26.

8. Marra HLD, Martin LM, Claudia MM, Debora A, Philip LR, Carlos G, dkk. Transcranial magnetic stimulation to address mild cognitive impairment in the elderly: a randomized controlled study. Behav Neurol. 2015;2015:287843.

9. Moraes FN, Ferreira SFB, Souza AMC, Diniz DS. Neuromodulation using transcranial magnetic stimulation (TMS): effective cognitive rehabilitation after stroke. Jornal Brasileiro de Neurocirurgia. 2016;27(2):149-54.

10. Miniussi C, Rossini PM. Transcranial magnetic stimulation in cognitive rehabilitation. neuropsychological rehabilitation. Neuropsychol Rehabil. 2011;21(5):579-601.

11. Luber B, Lisanby SH. Enhancement of human cognitive performance using transcranial magnetic stimulation (TMS). Neuroimage. 2014;85(3):961-70.

12. Li Y, Wang L, Jia M, Guo J, Wang H, Wang M. The effects of high-frequency rTMS over the left DLPFC on cognitive control in young healthy participants. Pubmed PLoS One. 2017;12(6):e0179430. 